\title{
Cascade PI-Fuzzy Based Position Optimization of Nonal Switched UPQC with DG for Power Quality Enhancement in IEEE 14 Bus System
}

\author{
H. R. SUKHESH \\ P.G. Student of Electrical Engineering \\ People Education Society University \\ Bangalore, Karnataka, INDIA.
}

\author{
SENTHIL VADIVU U. \\ Faculty of Electrical Engineering \\ People Education Society University \\ Bangalore, Karnataka, INDIA.
}

\begin{abstract}
An Unified Power Quality Conditioner (UPQC), owning the composition of shunt and series Active Power Filter (APF), has become a standard accepted solution in the area of current and voltage harmonics mitigation of a power system network. This paper furnishes a novel approach of nonal switched UPQC topology, supported with Distributed Generation (DG), aiming at the power quality enhancement and position optimization, placed at different locations in a standard IEEE 14 bus system. In addition to this, behaviour of the proposed topology is analysed using novel Cascade Proportional Integral (PI) - Fuzzy and Space Vector Pulse Width Modulation (SVPWM) as control algorithms and the outcomes are compared with the historical twelve switch UPQC topology. Simulation results of the proposal modelled in MATLAB/SIMULINK reveals the superiority of nonal switched UPQC and the optimal position of the proposed conditioner, for mitigating the harmonic issues in the standard IEEE 14 bus system.
\end{abstract}

Keywords - Nonal switched UPQC, IEEE 14 bus system, Cascade PI-Fuzzy, SVPWM, Power Quality (PQ).

Received: September 25, 2020. Revised: March 3, 2021. Accepted: March 21, 2021. Published: April 8, 2021.

\section{Introduction}

In the current booming world, survival is inconceivable without the usage of electric power. Hence electrical energy plays a leading role. Assisting this, it is essential to promote the uninterrupted sustainable quality of electrical power to the end user, as many customer loads mandates the continual distortion free supply. But, the usage of soft switching devices and the nonlinear loads in the power system causes heating, harmonics, flickers and many other disturbances which will impact the system's availability and reliability.

To dilute the power quality issues, power quality monitoring equipment and power quality conditioners should be lodged in the distribution side to curb the harmonics, voltage sags, voltage swell, etc.

Rahul Virmani presented a work on the "Performance Comparison of UPQC and Active Power Filters for a NonLinear Load". This work transparently remarks the advantages of implementing the UPQC into the power system, when compared with an APF. The control algorithm is recommended to diminish the harmonics, but with the need of excessive memory consumption [1].

The research titled "A Low Cost High Performance UPQC for Current and Voltage Harmonics Compensations" carried out by Quoc-Nam from Korea, suggest the use of low cost, high performing UPQC devices in a power system. They further proposed that the insertion of a capacitor in succession to shunt APF, will considerably curtail the voltage across the DC link [2].

Mohammed Abdul Ahad Yahiya's work on "Performance Analysis of DVR, DSTATCOM and UPQC for Improving the Power Quality with Various Control Strategies" compares the voltage quality enhancement techniques implemented using DVR, D-STATCOM and UPQC, actuated with PI controller and FLC, but are computationally rigorous because of the complex algorithm with inefficient memory management [3].

Vinod Khadkikar revealed a new comprehensive review on the divergent possible UPQC topologies for single and three phase networks, to enhance the power quality [4].

Supplementing these, few conventional solutions for power quality improvement were still debatable due to inefficient algorithms, over consumption of memory and less impact on harmonics. Addressing these, there are noticeable advancements attempted in the literatures [5]-[10].

In this proposed methodology, the nonal switched UPQC topology is implemented along with DG, implanted in different locations of an IEEE 14 bus system which are controlled with the Cascade PI-Fuzzy and SVPWM control algorithms. Supporting this, the results are contrasted with twelve switch UPQC topology with the same stated control strategies. The simulation results, proving its effectiveness in harmonics reduction at different optimal location are presented.

The organization of the proposed work is as follows. Section II evokes the control strategies implemented in this research for UPQC. The detailed UPQC Configurations are given in Section III. Section IV presents the IEEE 14 Bus system. Section V documents the simulation results, and the conclusion of this work is reported in the Section VI.

\section{Control Strategy}

The key idea of control strategy is to calculate and facilitate the injection of required quantity of the voltage and current signals to improvise the compensation effect in the system. To 
accomplish this, Cascade PI-Fuzzy and SVPWM are proposed in this research.

\subsection{Cascade Pi-fuzzy Control Strategy}

The modelled, simulated and executable structure of a novel Cascade PI-Fuzzy control strategy is depicted in the Fig. 1. It consists of a PI controller cascaded with the Fuzzy Logic Controller (FLC) (represented as a green colored blocks).

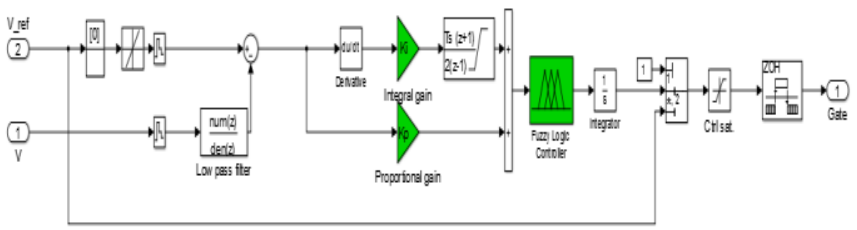

Fig. 1. Simulation structure of Cascade PI-Fuzzy control strategy.

The modular layout of a fuzzy controller is composed of Fuzzification, Inference engine, Defuzzification blocks [11].

The approach of restyling the input/output variable to linguistic labels is entitled as fuzzification. In the proposed methodology, 07 classes of linguistic labels namely: Large Positive (LP), Medium Positive (MP), Small Positive (SP), Zero (ZE), Small Negative (SN), Medium Negative (MN), Large Negative (LN) projected over there membership grades are used, to decompose each system variable into fuzzy regions having the range [-1 1 ].

Inference Engine: The performance of the FLC, relating the input and output variables of the system is influenced by a set of rules. These rules relating the error and its rate of change are depicted in Table 1. Based on this, 49 rules are formed and are designated as the Knowledge repository of the FLC.

TABLE I. FUZZY CONTROL RULES

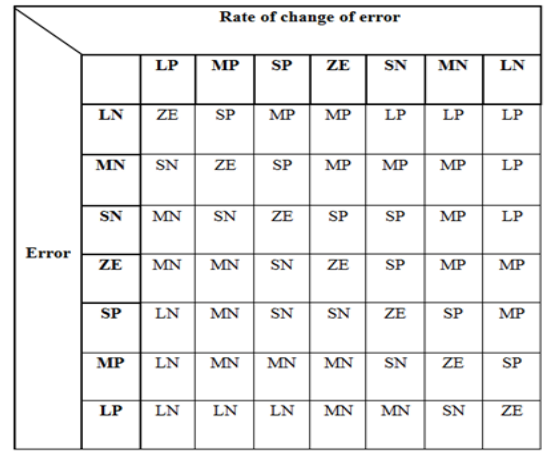

Defuzzification: The fuzzy set has to be altered into crisp solution variable before it can be used to control the system. This is realized by using a defuzzifier block.

\subsection{SVPWM Control Strategy}

The execution structure of SVPWM involves conversion of signals form $a, b, c$ frame to $d-q$ frame and further from $d-q$ frame to $a, b, c$ frame. It effectively utilizes the space vector theory to calculate the duty cycle and finally to generate the gate pulse for APF.
The advantages offered by the implemented SVPWM control strategy are low switching loss, less THD in the spectrum of switching waveform, low implementation complexity and reduced computational difficulties with optimal memory consumption.

\section{UPQC Configurations}

In this section, two configurations of 3- $\phi$ UPQC systems, used to mitigate the power quality problems, are described.

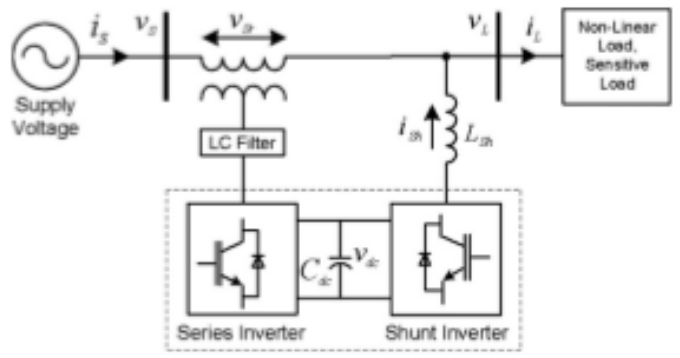

Fig. 2. General structure of UPQC.

The Fig.2 represents the general outline of UPQC. It is comprised of two 3- $\phi$ active voltage source inverter filters namely Series Active Filter (SAF) and Parallel Active Filter (PAF), associated in sequence with a common DC Link. The $\mathrm{SAF}$ is in series with the line and operates to compensate the voltage quality problem in the line. The PAF is in shunt to the line aiming to compensate the current quality problem in the line and to regulate the DC link. Figure 3 depicts the 3P3W VSI-based UPQC topology involving 12 switches, ultimately feeding 3P3W load. This is the most widely used and commonly studied configuration.

In addition to this, a novel topology named 3P3W VSIbased UPQC topology involving 9 switches is proposed, which is as described in the Fig. 4. The switch count has been reduced by $33 \%$ than the historical 12 switch UPQC topology, without considerably sacrificing in the ideal performance.

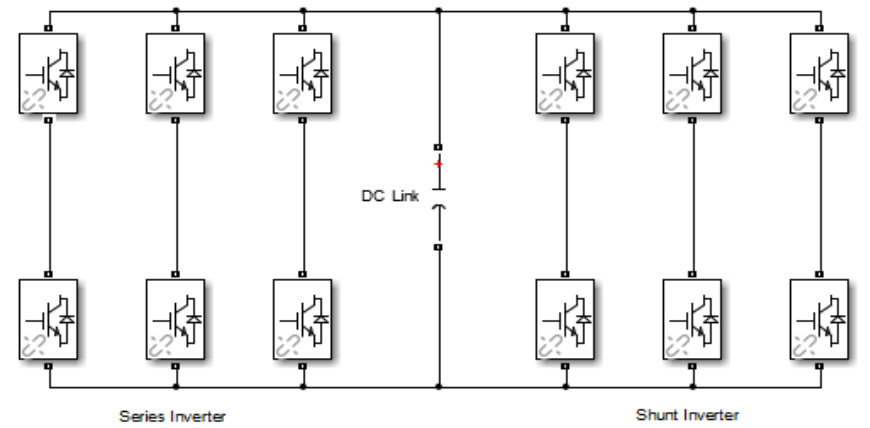

Fig. 3. 3P3W UPQC topology with 12 switches. 


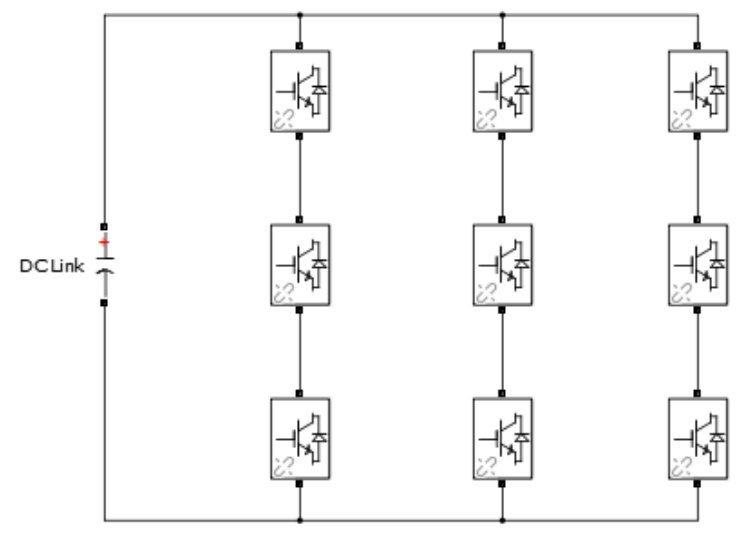

Fig. 4. 3P3W UPQC topology with 9 switches.

\section{I( ( ( 14-bus System}

Single line layout of the IEEE 14-Bus standard system is showcased in Fig. 5 with loads presumed to be with constant impedance and all generators run with constant mechanical power input and with fixed excitation. It composes of 05 number of synchronous rotating devices with IEEE typelexciters, 03 number of them are synchronous compensators used only for reactive power support with generator 1 considered as a reference generator.

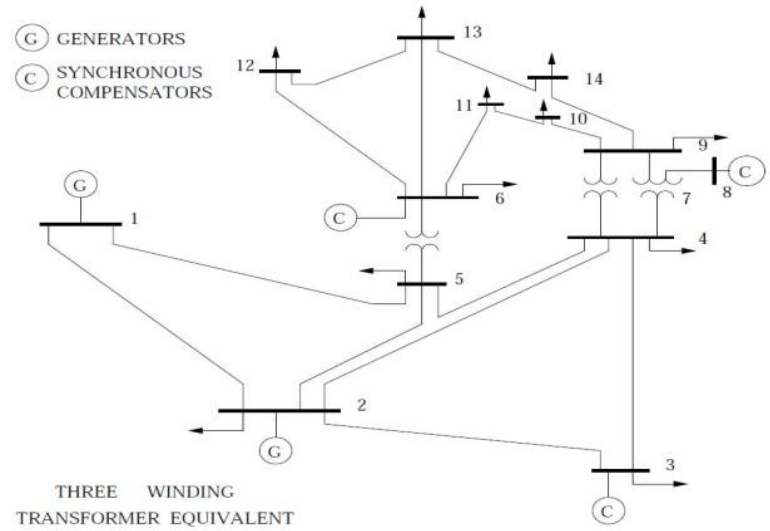

Fig. 5. IEEE 14 Bus test system

\section{Simulation Results}

To enable the comparative harmonic analysis of the two stated UPQC configurations, gated with two control strategies namely cascade PI-Fuzzy and SVPWM and to optimize their location, the proposed UPQC models are constructed in the MATLAB/SIMULINK environment. The Fig. 6 shows the detailed SIMULINK model of a 3P3W UPQC configuration, fired with cascade PI-Fuzzy method. It consists of a 3- $\phi$ voltage source rated $400 \mathrm{~V}, 50 \mathrm{~Hz}$ feeding a critical $3-\phi$ load through the power transformers and transmission line.

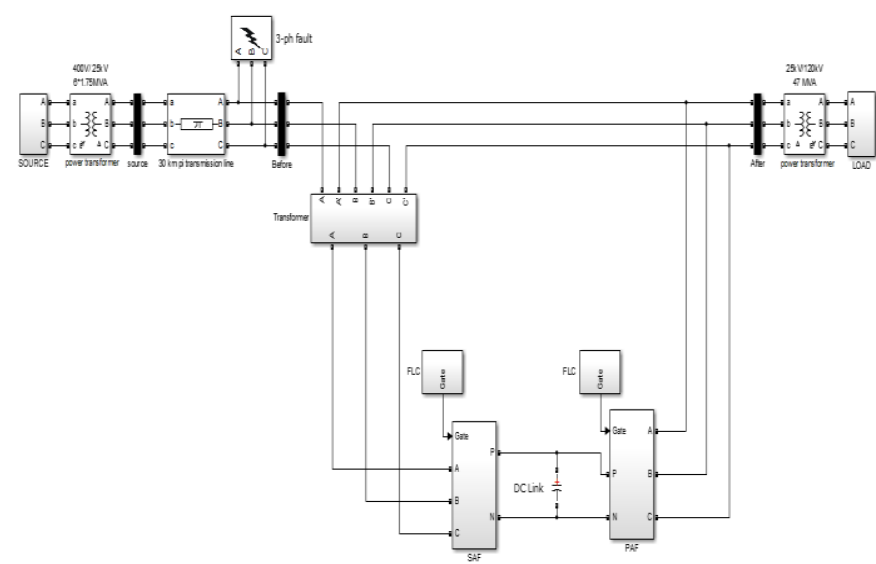

Fig. 6. Simulink model 3P3W UPQC configuration

The SAF and PAF are realized using IGBT bridge circuit with 12 switches. The $3-\phi$ to ground fault having short circuit transition time of [0.15-0.3] s, is also simulated. Similarly, the other proposed configuration namely 9 switches topology is also modeled in the SIMULINK and successfully executed. The UPQC models are placed in between all the branches of an IEEE 14 Bus system. The UPQC are gated through cascade PI-Fuzzy and SVPWM separately and the harmonic analysis of voltage and current waveforms, (for phase A), measured before compensation and after compensation for both the two stated UPQC configurations are accomplished and the results are processed through the harmonic FFT analysis.

Fig. 7 shows the voltage waveforms before compensation and after compensation and Fig. 8 represent the current waveforms before compensation and after compensation for 3P3W configuration, placed between Bus 1 and Bus 2 of IEEE 14 Bus system. Both the figures indicating three phase waveforms in phases $\mathrm{A}, \mathrm{B}$ and $\mathrm{C}$ are represented by the red, blue and green lines respectively.

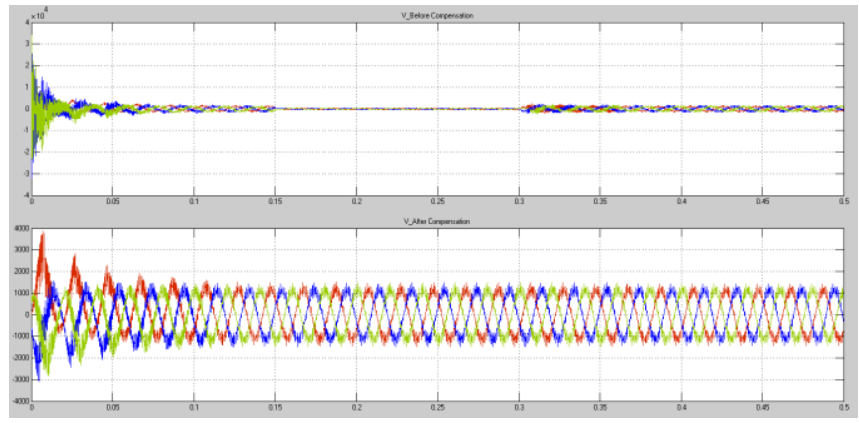

Fig. 7. Simulated results of voltage waveforms 


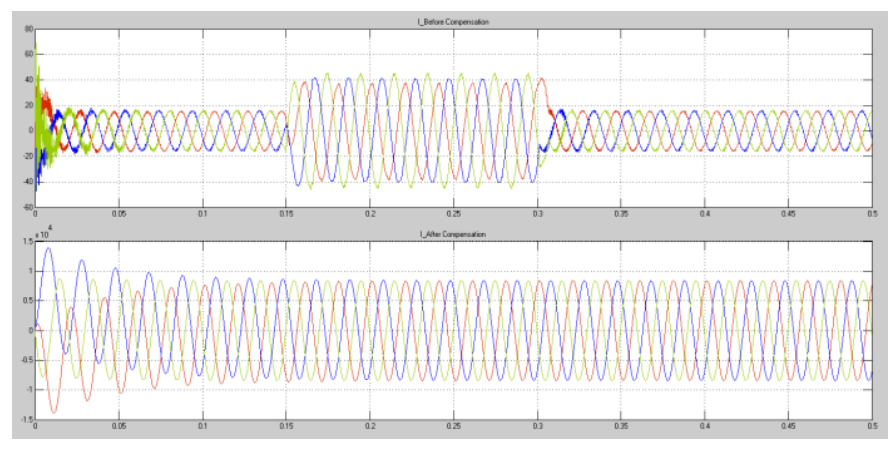

Fig. 8. Simulated results of current waveforms
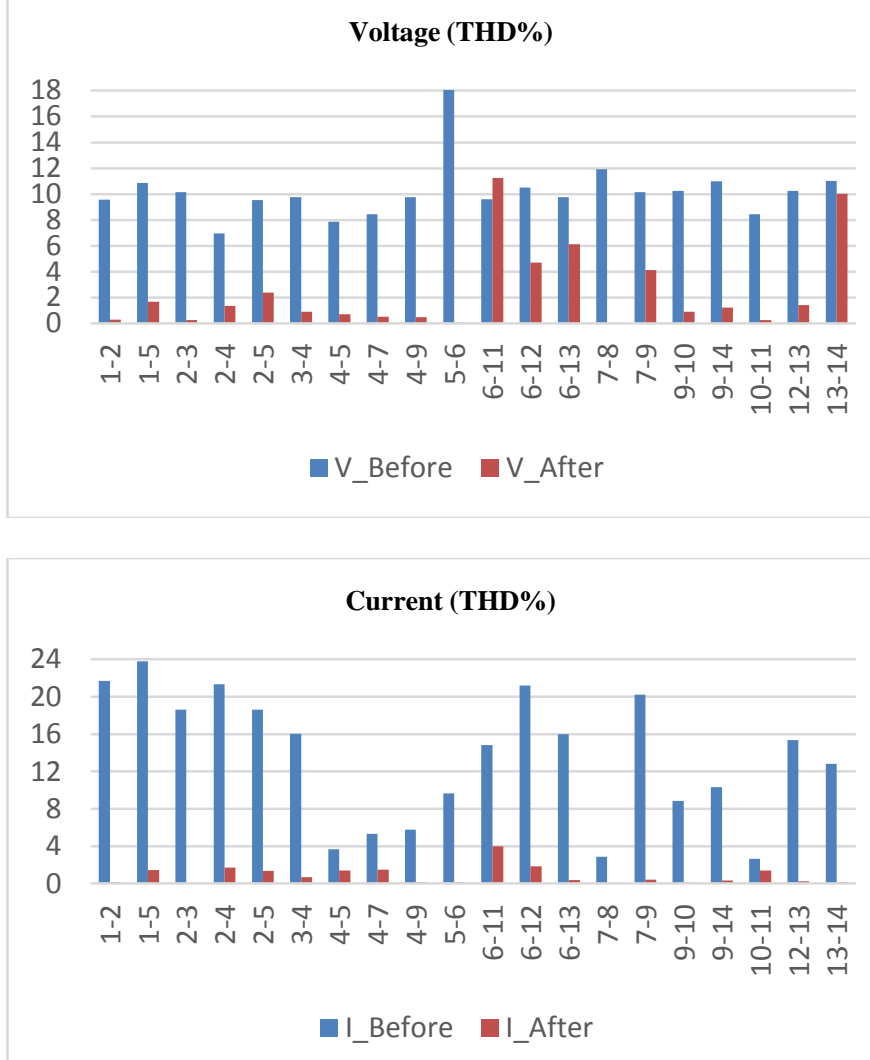

Fig. 9. Harmonic data of 3P3W topology with 12 switches and Cascade PIFuzzy

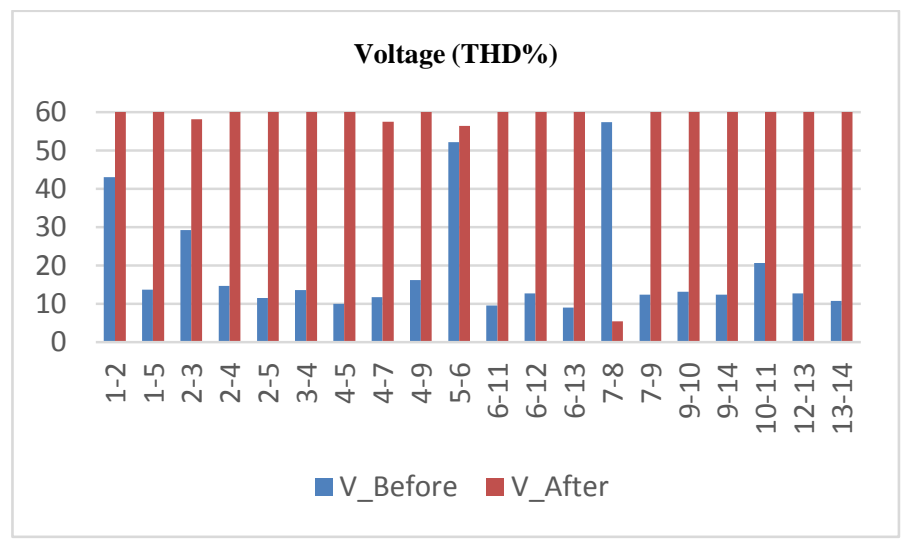

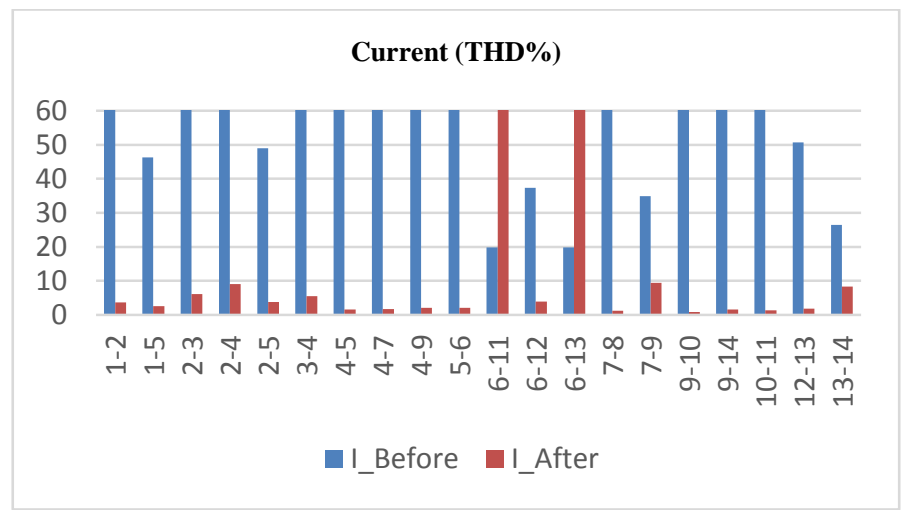

Fig. 10. Harmonic data of 3P3W topology with 12 switches and SVPWM
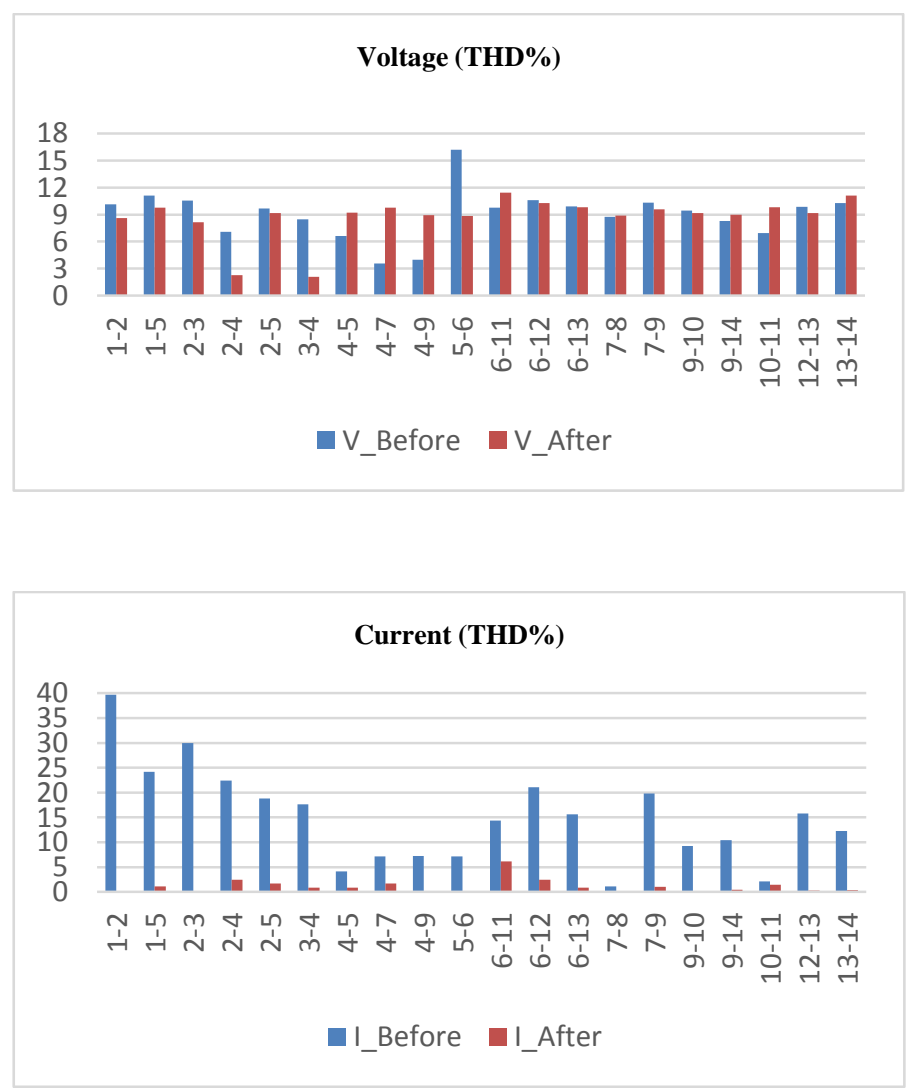

Fig. 11. Harmonic data of 3P3W topology with 9 switches and Cascade PIFuzzy

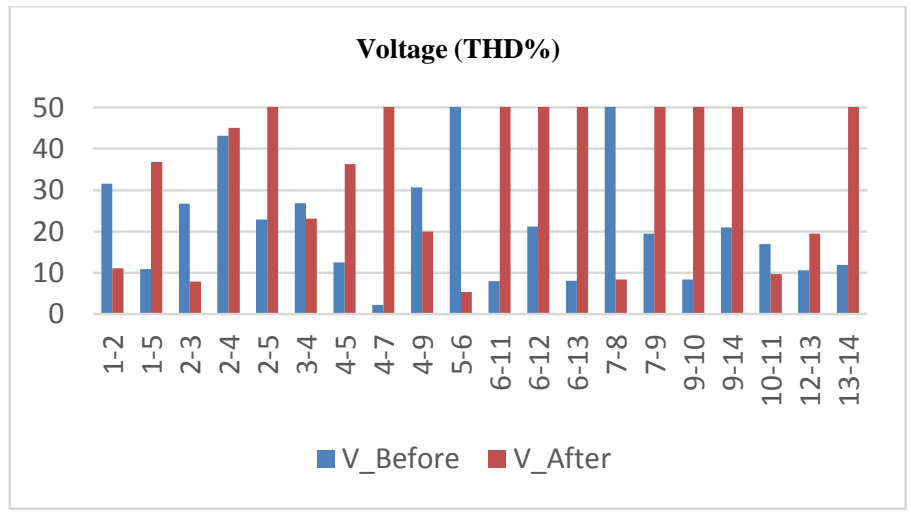




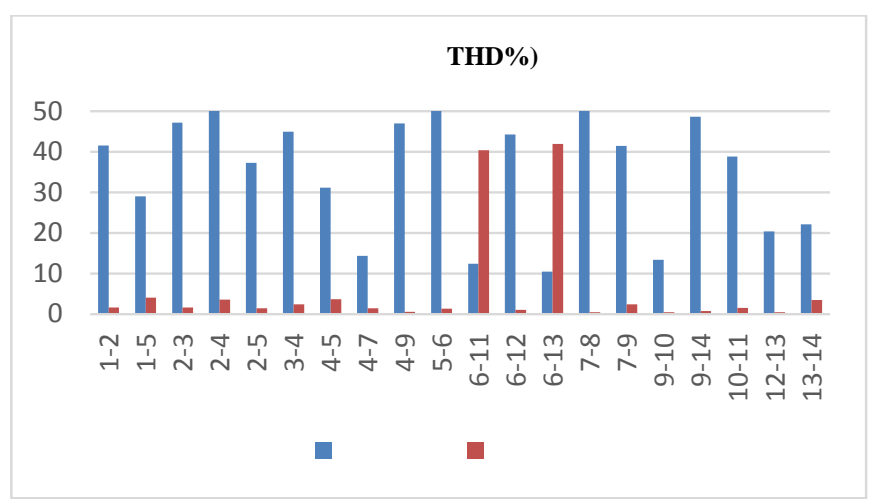

Fig. 12. Harmonic data of 3P3W topology with 9 switches and SVPWM

\section{Conclusion}

Power quality issues such as voltage sag and swell are most commonly occurred in the power distribution system. To overcome these issues, different topologies of UPQC are proposed in this paper. To enhance the power quality, 12 switch UPQC with Cascade PI-Fuzzy and 12 switch UPQC with space vector pulse width modulation, are implemented in MATLAB Simulink to minimize the voltage sag under different configurations. Further, the results of above stated configurations are compared with the novel 9 switch UPQC with cascade PI-Fuzzy and 9 switch UPQC with space vector pulse width modulation configurations, which are also simulated.

From the harmonic analysis, it is clearly indicated that the for 3P3W UPQC topology with 12 switches and gated with cascade PI-Fuzzy (Fig. 9), placing the UPQC in between bus 7 and bus 8 will be the optimal location, where both the voltage and current harmonic level can be drastically reduced to $0.03 \%$ and $0.07 \%$ respectively. If current harmonic is of concern, then the placing the UPQC in between bus 2 and bus 3 is an optimal choice, where the current harmonic level is reduced to $0.04 \%$.

For 3P3W UPQC configuration with 12 switches and gated with SVPWM (Fig. 10), placing the UPQC in between bus 7 and bus 8 will be the optimal placement, where the voltage harmonic level can be managed to $5.43 \%$ and current harmonic level can be controlled to $1.16 \%$. If current harmonic is of interest, then the placing the UPQC in between bus 9 and bus 10 is an optimal choice, where the current harmonic level is reduced to $0.85 \%$.

Similarly, for 3P3W UPQC topology with 9 switches and gated with cascade PI-Fuzzy (Fig. 11), placing the UPQC in between bus 3 and bus 4 will be the optimized position of placement, where the voltage and current harmonic level can be quenched to $2.08 \%$ and $0.84 \%$ respectively. If current harmonic is of importance, then the placing the UPQC in between bus 7 and bus 8 is an optimal one, where the current harmonic level is reduced to $0.04 \%$.

Likely, for 3P3W topology with 9 switches and gated with SVPWM (Fig. 12), placing the UPQC in between bus 5 and bus 6 will be the optimized target, where both the voltage and current harmonic level can be hindered to $5.32 \%$ and $1.37 \%$ respectively. If current harmonic is of concern, then the placing the UPQC in between bus 7 and bus 8 is an optimal choice, where the current harmonic level is reduced to $0.43 \%$.

\section{References}

[1] R. Virmani, P. Gaur, H. Santosi, A. P. Mittal, and B. Singh, "Performance comparison of UPQC and active power filters for a nonlinear load," 2010 Jt. Int. Conf. Power Electron. Drives Energy Syst. PEDES 20102010 Power India, 2010.

[2] Q. N. Trinh and H. H. Lee, "A low cost high performance UPQC for current and voltage harmonics compensations," IEEE Int. Symp. Ind. Electron., pp. 341-346, 2014.

[3] M. A. A. Yahiya and M. A. R. Uzair, "Performance analysis of DVR, DSTATCOM and UPQC for improving the power quality with various control strategies,” 2016 - Bienn. Int. Conf. Power Energy Syst. Towar. Sustain. Energy, PESTSE 2016, 2016.

[4] Khadkikar, "Enhancing electric power quality using UPQC: A comprehensive overview," IEEE Trans. Power Electron., vol. 27, no. 5, pp. 2284-2297, 2012.

[5] Sukhesh H R, Senthil Vadivu U and Prabhakar Karthikeyan, "Optimal Placement of Fuzzy Based UPQC Topologies for Power Quality Enhancement in the IEEE 14 Bus System", World Summit on Advances in Science, Engineering and Technology, Cambridge, UK, 2018.

[6] Antar Beddar, Hacene Bouzekri, Badreddine Babes and Hamza Afghoul, "Experimental enhancement of fuzzy fractional order PI+I controller of grid connected variable speed wind energy conversion system", An International Journal of Energy Conversion and Management, Vol.123, pp.569-580, 2016.

[7] A.Jayaprakash and D.Jananisri, "Grid connected renewable energy system using unified power quality conditioner for improving power quality", An International Journal of Innovative Research in Computer and Communication Engineering, Vol.2, No.1, 2014.

[8] G.Laxminarayana and G.Umesh Kumar, "Power Quality Improvement Using UPQC for Wind Farm Generation System", An International Journal of Advanced Research in Electrical, Electronics and Instrumentation Engineering, Vol.1, No.6, 2012.

[9] EaswaraMoorthy Nanda Kumar, R. Dhanasekaran and Sundararaj Nanda Kumar, "Simulation of Optimal Power Flow incorporating with Fuzzy Logic Control and various FACTS Devices", An International Journal of Scientific and Research Publications, Vol.2, No.5,pp.1-5, 2012.

[10] M.Kesraoui, N.Korichi and A.Belkadi, "Maximum power point tracker of wind energy conversion system", An International Journal of Renewable Energy, Vol.36, pp.2655-2662, 2011.

[11] H. R. Sukhesh, and M. Mahesh, "Comparative analysis of the behaviour of EKF algorithm integrated classical PI controller and cascade PI-fuzzy controller", 2017 International Conference on Electrical, Electronics, Communication, Computer and Optimization Techniques, Mysore, pp. 393-398, 2017.

\section{Contribution of Individual Authors to the Creation of a Scientific Article (Ghostwriting Policy)}

The authors equally contributed in the present research, at all stages from the formulation of the problem to the final findings and solution.

\section{Sources of Funding for Research Presented in a Scientific Article or Scientific Article Itself}

No funding was received for conducting this study.

\section{Conflict of Interest}

The authors have no conflicts of interest to declare that are relevant to the content of this article.

Creative Commons Attribution License 4.0 (Attribution 4.0 International, CC BY 4.0)

This article is published under the terms of the Creative Commons Attribution License 4.0 https://creativecommons.org/licenses/by/4.0/deed.en 